UCRL-ID-121252

\title{
Status Report on Preliminary Assessment of Variations of Regional Phases and Discriminants with Distance
}

Peter Goldstein

Craig Schultz

June 5, 1995

- Work performed under the auspices of the U.S. Department of Energy by the Lawrence Livermore National Laboratory under Contract W-7405-Eng-48. 


\section{DISCLAIMER}

Portions of this document may be illegible in electronic image products. Images are produced from the best available original document. 


\section{Status Report on Preliminary Assessment of Variations of Regional Phases and Discriminants With Distance} Peter Goldstein and Craig Schultz Lawrence Livermore National Laboratory

\section{Introduction}

Performance and portability of regional discriminants:

An improved understanding of the variability of regional seismic phases with distance is needed to improve the performance and transportability of regional seismic discriminants. Observations of large variations in regional phase amplitudes, over relatively short distances, are not uncommon. For example, large variations in Pn amplitudes of the Non-Proliferation Experiment (NPE) were observed along lines to the west (e.g., Keller et al., 1994), and northwest (e.g., McCormack et al., 1994). Numerous studies, in a number of areas, have also observed large variations in $\mathrm{Sn}$ and $\mathrm{Lg}$ over relatively short distances (e.g., Kadinsky-Cade et al., 1981; Ni and Barazangi, 1983). An improved understanding of these variations has been gained from numerous empirical observations (e.g., Chavez and Priestley, 1984; Zhang et al., 1994) and theoretical studies (e.g., Campillo, 1990, Kennett, 1993). We are developing a number of techniques and procedures for characterizing such features on a region specific basis. 
Variations in $\mathrm{Pn}, \mathrm{Pg}$, and $\mathrm{Lg}$ and Numerical Modeling

As part of our efforts to develop procedures for regional geophysical characterization we have been making and assembling empirical observations on regional phase propagation. At the same time, we have been developing numerical models to describe the observed phenomena and are collaborating with researchers at U.C. Santa Cruz to do statistical analyses of the sensitivity of various regional phases to various crustal parameters.

Examples of some of the work we are doing include measurements and modeling of the variability of regional $\mathrm{Pn}, \mathrm{Pg}$, and $\mathrm{Lg}$ signals from the NPE along lines to the east, west, and northwest. For modeling purposes, we are developing fairly general numerical techniques that can include effects such as resonances in low velocity near surface layers, effects of surface and Moho topography, effects of alluvial basins, and effects of random scattering. An understanding and ability to predict the effects from all of these structures is considered important for regional geophysical characterization.

Preliminary results from the above work include, vertically stratified, one-dimensional models of near receiver structure that can explain much of the observed large amplitude Pn variability from the NPE along a line to the northwest. Measurements along a line across the Sierras to the west of the NPE (Figure 1) have been used to estimate the depth to the Moho and suggest that a significant change in Moho depth in the vicinity of the west side of the Sierras is responsible for some of the large variations in Pn along this line (Figure 3).

\section{Significance for Seismic Discrimination}

Observations and modeling of variations in regional phases, both with distance and from region to region, are important because the detection, location, and identification of small magnitude events rely heavily on observations of these phases. For example, one of the most popular regional discriminants is based on the ratio of high-frequency $(6-8 \mathrm{~Hz}) \mathrm{Pn}$ to $\mathrm{Lg}$ spectral amplitudes. If 
one of these phases is more sensitive to variations in crustal structure such as Moho depth or topography, we would expect to observe significant variations from station to station or at a single station for events from different azimuths. Recordings of the NPE, along the line that extended across the Sierra Nevada Range (Figure 1), give an excellent example of the potential variability (Figure 3). We find large variations in Pn that map directly into the 6-8 $\mathrm{Hz}, \mathrm{Pn} / \mathrm{Lg}$ spectral amplitude ratio. There are also variations in $\mathrm{Lg}$, but in general they are much smaller than those in $\mathrm{Pn}$. If such variations are due to systematic changes in features like crustal thickness or topography they would be very sensitive to source to receiver distance or azimuth and could introduce large variability into discriminants such as $\mathrm{Pn} / \mathrm{Lg}$ spectral ratios. We are developing capabilities and models to explain the observed variations; this should allow us to predict what would be expected in other regions.

\section{Acknowledgments}

Stan Ruppert provided significant technical input for this report. Steve Jarpe's help converting the Sierra line SEGY data to SAC was greatly appreciated. Shawn Larsen, Dave Harris and a number of LLNL researchers are actively developing the numerical modeling capabilities mentioned in this report.

\section{Figure Caption:}

Figure 1. Map indicating the location of the seismic lines that recorded data to the west of the NPE. Large variations in Pn amplitude were observed along the east-west trending line (see Figure 3).

Figure 2. Cross section of topography above a registered record section plot of recordings from the NPE. Note the large variations in Pn amplitudes across the Great Valley.

Figure 3. Average 6 to $8 \mathrm{~Hz}$ spectral amplitudes of Pn (black triangles), $\mathrm{Lg}$ (red circles), and $\mathrm{Pn} / \mathrm{Lg}$ spectral ratios (blue diamonds) of the NPE along a west trending line crossing the Sierras. 


\section{References}

Campillo M. "Propagation And Attenuation Characteristics Of The Crustal Phase Lg”, Pure And Applied Geophysics, 13, 1-19, 1990.

Chavez, D. A., and K. F. Priestley, "Measurement of Frequency Dependent Lg Attenuation in the Great Basin", Geophys. Res. Lett. 13, 551-554, 1986.

Kadinsky-Cade, K.,M. Barazangi, J. Oliver, and B. Isacks, "Lateral Variations of High-frequency Seismic Wave Propagation at Regional Distances Across the Turkish and Iranian Plateaus, J. Geophys. Res., 86, 9377-9396, 1981.

Kennett B. L. N., "The Distance Dependence Of Regional Phase Discriminants", Bulletin Of The Seismological Society Of America, 83, 1155-1166, 1993.

Keller G. R., P. E. Malin, S. D. Ruppert, "Southern Sierra Nevada Continental Dynamics Project: 1993 Field Observations of the NPE", 1994, DOE symposium on the Non-Proliferation Experiment, April 19-21, 1994, Rockville Maryland.

McCormack , D. A., K. F. Priestley, H. J. Patton, "Distance Effects on Regional Discriminants Along a Seismic Profile in Northwest Nevada, NPE and Nuclear Results", 1994, DOE symposium on the Non-Proliferation Experiment, April 19-21, 1994, Rockville Maryland.

$\mathrm{Ni}$, J., and M. Barazangi, "High-frequency seismic wave propagation beneath the Indian Shield, Himalayan Arc, Tibetan Plateau and Surrounding Regions: High Uppermost Mantle Velocities and Efficient Sn Propagation Beneath Tibet", Geophys. J. Roy. Astr. Soc. 72, 665-689, 1983.

Zhang, T. R., S. Y. Schwartz, and T. Lay, "Multivariate Analysis Of Waveguide Effects On Short-Period Regional Wave Propagation In Eurasia And Its Application In Seismic Discrimination", J. Geophys. Res., 99, 21929-21945, 1994. 


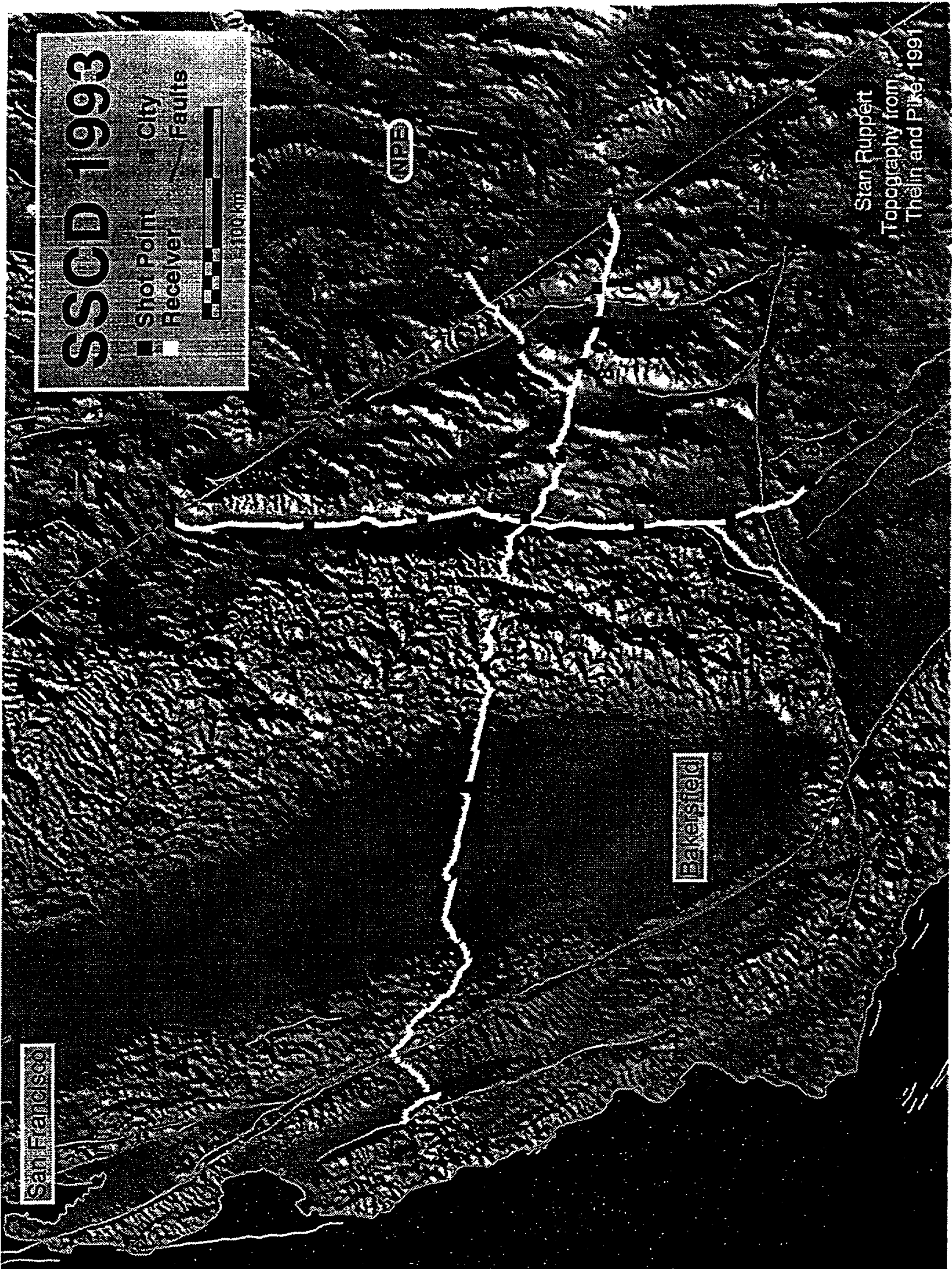




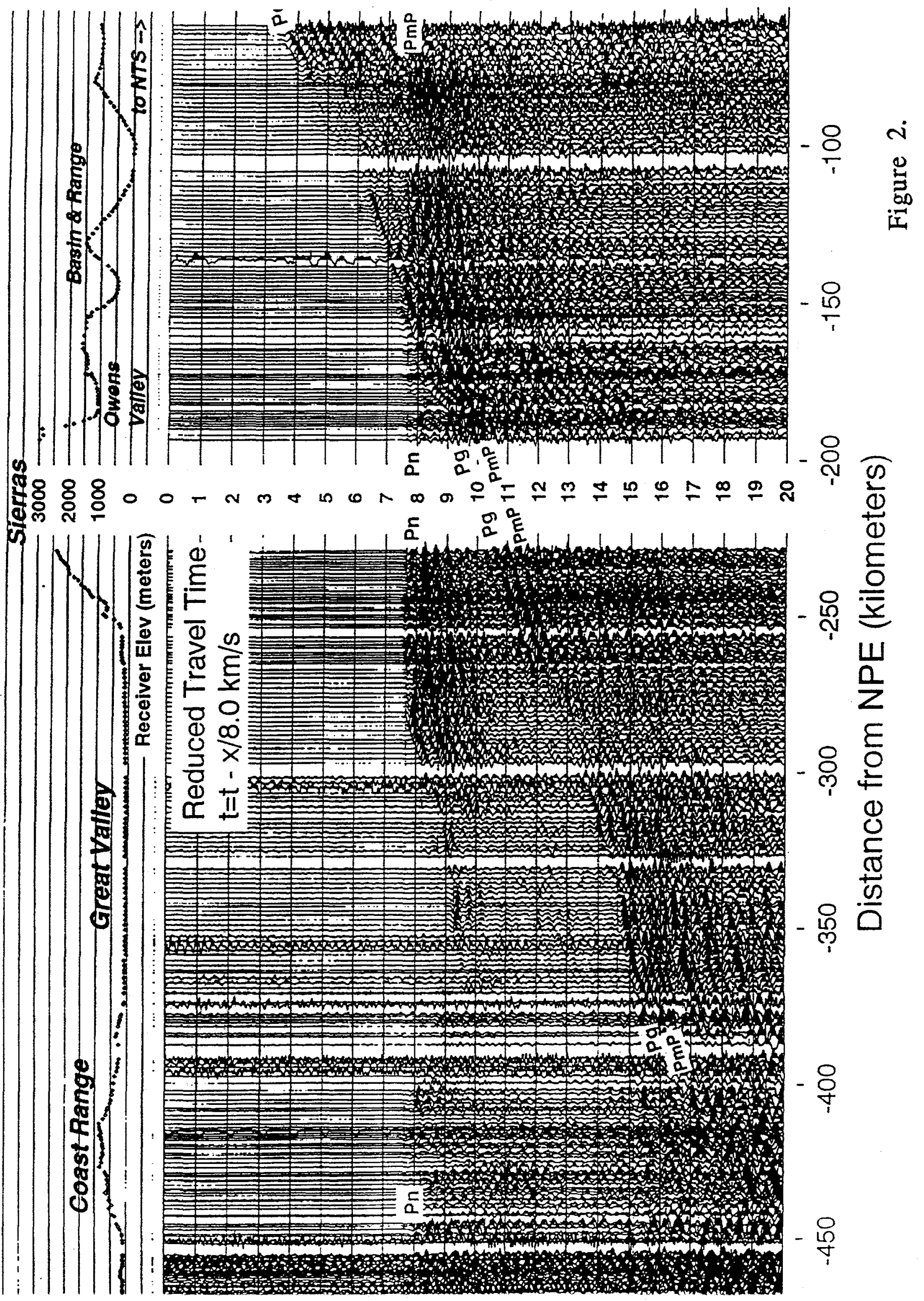




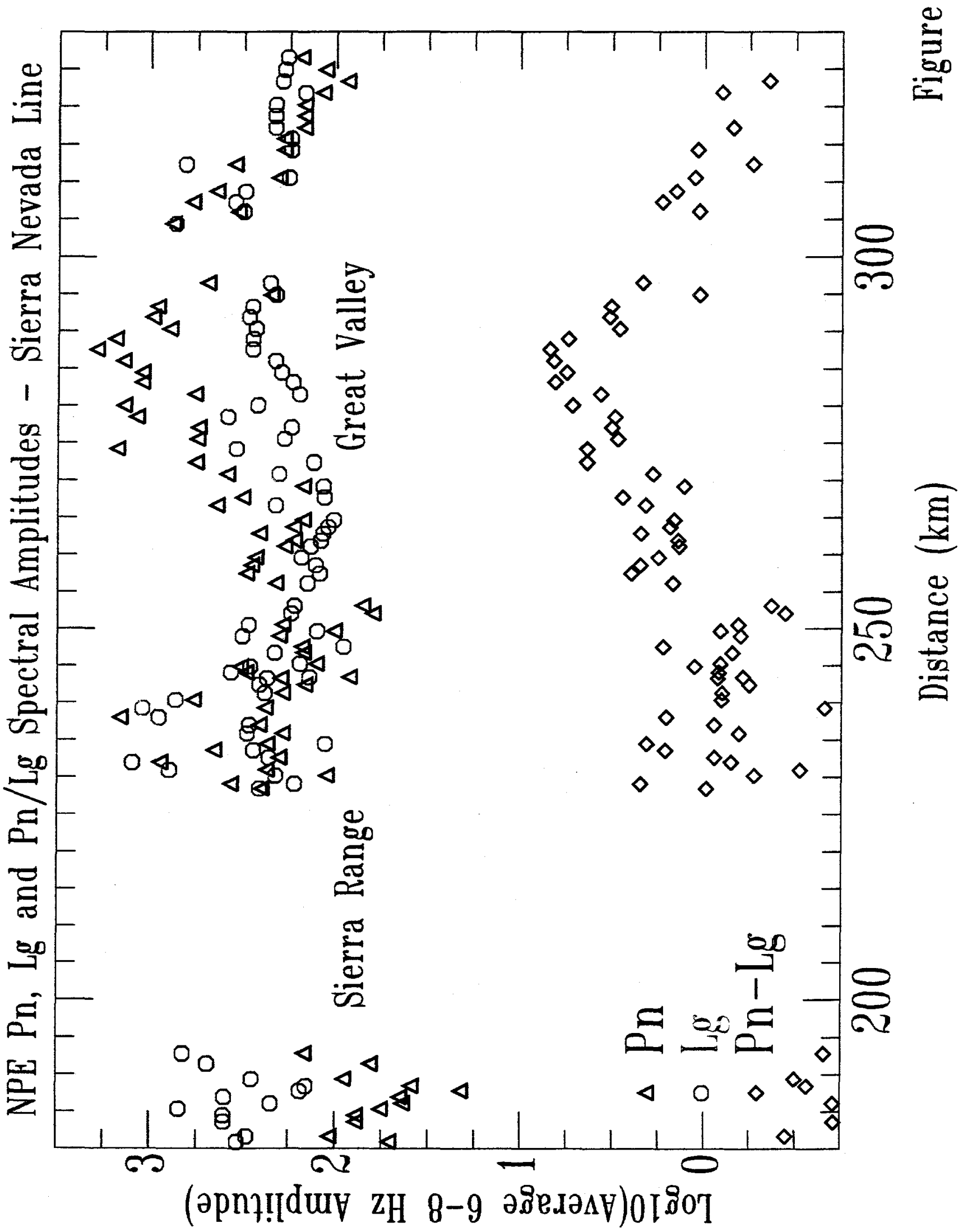

